\title{
EL PAPEL DE LAS NOTAS CRISTOLÓGICAS DEL NARRADOR EN EL EVANGELIO DE JUAN
}

\author{
José Manuel Hernández Carracedo \\ Universidad Pontificia de Salamanca \\ jmhcarracedo@hotmail.com
}

Resumen: En este artículo se quiere mostrar la importancia de las notas cristológicas del narrador para la adecuada comprensión del evangelio de Juan, tanto en su conjunto como en sus distintas partes y perícopas concretas. Tras definir lo que se considera una nota del narrador, se estudian tres notas en particular (Jn 1,17-18; 12,41; 20,30-31), que, por el lugar que ocupan en la narración, le confieren una determinada estructura: la de una vida antigua. Para confirmar esta hipótesis se describe, de forma breve, el papel que juegan las notas del narrador en las distintas partes del cuarto evangelio, como guía de lectura y de interpretación para el lector. De esta forma podemos concluir que el autor del cuarto evangelio adoptó, como los sinópticos, el género literario de vida antigua para conservar y transmitir la memoria de Jesús.

Palabras clave: Análisis narrativo. Narrador. Notas. Vida antigua. Cristología. Evangelio de Juan.

Titel: The Function of Narrator's Christological Notes in the Gospel of John.

Abstract: In this article we want to show the importance of the Christological notes of the narrator for the adequate understanding of the Gospel of John, both as a whole, as in its different parts and concrete pericope. After defining what is considered a note of the narrator, three notes are studied in particular (Jn 1,17-18; 12,41; 20,30-31), that by the place they occupy in the narrative give a certain structure: that of an ancient life. To confirm this 
hypothesis, briefly describes the role played by the narrator's notes, in the different parts of the fourth gospel, as a guide for reading and interpretation for the reader. In this way, we can conclude that the author of the fourth Gospel adopted, like the synoptics, the literary genre of ancient life to preserve and transmit the memory of Jesus.

Key Words: Narrative Analysis. Storyteller. Notes. Ancient life. Christology. Gospel of John.

\section{Introducción}

Hay dos rasgos característicos relevantes en el cuarto evangelio relacionados entre sí. El primero es literario, y se trata de los comentarios del narrador dentro del relato; el segundo es el interés cristológico de todo el relato, como el mismo autor señala al final de la narración (Jn 20,30-31). El acceso a la identidad de Jesús se alcanza por medio de la narración y su estrategia narrativa ${ }^{1}$; dentro de esta estrategia ocupan un lugar significativo los comentarios del narrador, que poseen, a nuestro juicio, un papel estructural en el relato.

Los comentarios explícitos del autor del cuarto evangelio han sido estudiados a lo largo de la historia de la investigación exegética por ser una de sus características literarias más significativas. Sin embargo, la novedad de este estudio radica fundamentalmente en dos cuestiones: el enfoque narrativo $^{2} \mathrm{y}$, dentro de este, el estudio concreto de determinados comentarios

\footnotetext{
1 ZUMSTEIN, “La rédaction finale”, 222.

2 Los comentarios del evangelista han sido utilizados a lo largo de la investigación de diversas formas y con distintos enfoques, pero casi todos centrados en la cuestión de la autoría del evangelio y de la crítica literaria y redaccional. En los estudios más antiguos, las intervenciones directas del autor daban pie a afirmar la veracidad histórica del relato. los estudios críticos los utilizan para reconstruir el trabajo redaccional experimentado por la obra y para discernir las distintas fuentes que le dieron origen. Se puede concluir que la crítica literaria ha contemplado estos comentarios del evangelio de Juan como algo característico de la obra, pero que solo han sido utilizados para describir sus distintas etapas redaccionales. Se constata que, pese a todo el esfuerzo, es difícil atribuir la autoría de cada uno de estos pasajes a una de las fases de la redacción, y menos aún a un autor, ya sea este el evangelista, el editor o el redactor. A partir de los años ochenta aparecen los primeros estudios narrativos aplicados al evangelio de Juan, que tampoco consideran los comentarios del evangelio como la clave de la crítica literaria.
} 
explícitos: los de la voz del narrador. Estos últimos reciben distintas denominaciones en la historia de la investigación: "notas a pie de página", "paréntesis", "glosas", "interpolaciones", "apartes". Aquí nos referiremos a ellos como "notas", aquello que se entiende por "advertencia, explicación, comentario o noticia de cualquier clase que en impresos o manuscritos va fuera del texto" ". En esta investigación, las notas se abordan desde la perspectiva narrativa y estudiando su función comunicativa, argumentativa y de caracterización de un personaje dentro de la trama.

El objetivo de este artículo es mostrar cómo algunos comentarios explícitos del narrador acerca de Jesús, a los que denominaremos notas, no solo le caracterizan y contribuyen a crear su identidad narrativa, sino que estructuran y guían al lector a lo largo de la trama del relato joánico. Para ello, en primer lugar se presentarán algunos aspectos introductorios: la comprensión del relato como una invitación al lector para reconfigurar su identidad a través de la identidad narrativa del protagonista de la narración; la función del narrador dentro del relato y la importancia de sus comentarios. Para finalizar la introducción se presentará el criterio que se ha utilizado para definir y delimitar el concepto de "nota del narrador", siguiendo los criterios aportados por las modernas teorías de la enunciación, lo cual permite distinguir estos de otros comentarios del narrador que no se pueden considerar "notas". En segundo lugar se estudian tres notas del narrador: Jn 1,17-18; 12,41; 20,30-31. Se mostrará que, por su contenido, su posición en la narración y por la relación que mantienen entre sí, confieren al relato una estructura determinada, que puede ser reconocido como una "vida antigua". Por lo cual, para finalizar el estudio, comprobaremos esta hipótesis describiendo, de forma sumaria, de qué modo las notas del narra-

Estos estudios buscan descubrir la especificidad del texto en sí mismo, ya que el sentido de un texto no se puede separar del texto mismo. Para la crítica narrativa, el texto es un vehículo de significados y de estrategias que buscan suscitar determinadas respuestas en el lector. Los trabajos narrativos trasladan su atención del autor al texto y al lector. La interpretación de los relatos tiene que tener en cuenta la lengua, el tono y la estructura de la obra, junto con el papel del narrador y del autor implícito. Prestando una especial atención al punto de vista del narrador y a sus comentarios tanto explícitos como implícitos en la evolución de la trama. Para un conocimiento del tema y de la historia de la investigación: TENNEY, “The Footnotes", 350-364; O'Rourke, “Asides", 211; VAN Belle, Les parenthèses; HEDRICK, “Authorial Presence", 74-93. VAN BELLE, “Les parentheses johanniques"; Sheeley, Narrative Asides; Thatcher, "A New Look at Asides"; Zumstein, "Process de relecture".

3 Diccionario de la lengua española, ad. loc. 
dor referidas a Jesús, a las que denominaremos "notas cristológicas" ${ }^{4}$, en cada una de las partes del relato centran el interés del lector en la identidad de Jesús y cumplen con los objetivos típicos de las vidas antiguas.

La aportación de este estudio es significativa, ya que las notas del narrador representan el punto de vista normativo del relato, que, a través de ellas, el narrador se dirige directamente al lector para guiar su lectura y su comprensión de la narración y de la identidad de los personajes.

\section{Algunos aspectos del método narrativo}

\subsection{El método narrativo y la identidad de los personajes}

Jean Zumstein ha expresado de forma clara la finalidad del método narrativo. Dicho fin consiste en reconstruir las operaciones por las cuales una obra se eleva sobre el fondo opaco del vivir para ser donada por un autor a un lector, que al recibirla es pro-vocado a cambiar su actuar. El texto se convierte en la mediación por la que el hombre, alejándose de sí mismo, se comprende a sí mismo. Gracias al texto se accede a nuevas posibilidades de ser en el mundo. El lector, contrastado por el relato, es confrontado con una redescripción de la realidad llena de nuevas posibilidades, y así el texto se convierte en una posibilidad de reconfigurar la comprensión del mundo y de la vida 5 .

${ }^{4}$ El estudio se centra en los comentarios del narrador que se refieren a Jesús, a sus acciones, palabras, sentimientos. No son objeto directo de este estudio los comentarios implícitos del narrador (malentendidos, ironía...) o aquellos comentarios atribuidos por la exégesis al autor o a un editor que no aparezcan como discurso del narrador.

5 ZUMSTEIN, “Narrativité et herméneutique”, 327-335. José Jiménez Lozano expresa el mismo fin para todo relato: “... el hecho es que quien lee u oye la historia contada o la norma que se dicta, escruta esa escritura y cuenta luego algo a su respecto, con frecuencia una nueva historia sobre la historia leída, y como iluminación de la propia historia [...] Porque el contar una historia de una manera a la vez fiel, pero distinta, y, desde la niñez, el leer una historia u oírla contar, tiene ya una doble vertiente: en primer lugar, la necesidad dolorosa o placentera de revivir una historia de hombres, y luego como medio de conocimiento de lo real y del hombre en su dimensión existencial y no en su mera res extensa [...] El libro invade o desposa la vida del lector y su destino. Es siempre susceptible de ser reinterpretado y, por tanto, tornado contemporáneo, y el mismo libro rejuvenece al lector, porque le dice siempre algo nuevo" (J. JIMÉnez LozAno, La Biblia y el invento de narrar, 16-17, en http://www.editorial confluencias.com/wp-content/pdf-paginas/JIMENEZ-LOZANO-\%5B13-27\%5D.pdf) Y en otra parte: "El relato es la primera forma de conocimiento, pero es obvio que la existencialidad del hombre, su vivir, solo a través del relato puede ser conocido" (ARBONA, Las llagas y los colores del mundo, 112). 
El propio narrador, al finalizar su narración, informa al lector del objetivo del relato: "... estas han sido escritas para que creáis que Jesús es el Cristo, el Hijo de Dios, y para que, creyendo, tengáis vida en su nombre" (Jn 20,31). En este versículo, el narrador da tres informaciones importantes para comprender la naturaleza y la finalidad de su obra: el evangelio es una narración que revela la identidad de Jesús como el Cristo, el Hijo de Dios, para crear una relación entre los lectores y Jesús por medio de la fe. De esta forma, el lector reconfigura su propia vida convirtiéndose en creyente.

\subsection{El papel del narrador en el relato}

El trabajo de referencia de los estudios narrativos del cuarto evangelio sigue siendo el de R. A. Culpepper ${ }^{6}$. Para este autor, el papel que juega el narrador en el relato es de suma importancia, por lo cual la figura del narrador debe ser estudiada con especial interés y distinguir su voz de la del autor real del texto o de la del autor implícito ${ }^{7}$. El narrador es la voz que habla en el prólogo del evangelio, cuenta la historia, proporciona explicaciones, traduce y descubre al lector lo que conocen o ignoran los personajes. Es intrusivo y a la vez fiable para el lector, al que proporciona toda la información necesaria para comprender correctamente su obra. Sus intervenciones no son glosas, sino partes fundamentales del texto que se distribuyen a lo largo de la trama, introduciendo a los lectores en su sistema de valores y de ideas. Sus comentarios interpretativos tienen la función de vehicular el desarrollo argumental. El narrador aparece como el que conoce completamente a Jesús, ya que comparte su omnisciencia, su ideología y sus mismas expresiones ${ }^{8}$. Su voz aparece como un guía fiable de lo que Jesús y su entrega, muerte y glorificación significan, conduciendo al mismo tiempo al lector por la sucesión de los acontecimientos del evangelio.

El narrador no solo cuenta una historia, sino que, al contarla, la interpreta. En nuestro caso, adopta la perspectiva de un grupo que defiende la fe en Jesús tras la resurrección, consciente de que el Paráclito actúa en su interior. De este modo proporciona una lectura del ministerio de Jesús a la luz de la gloria de Cristo resucitado y a la luz de su sensibilidad histórica y la vida de la comunidad ${ }^{9}$.

"Culpepeer, Anatomy; Culpepeer, “The Narrator", 81-96.

7 Culpepper, “La narratologie”, 101.

8 Culpepper, Anatomy, 36.

9 Ib., 29-30. 
En el campo del análisis narrativo, uno de los aspectos que se deben estudiar son las formas de discurso (plano fraseológico) que el narrador adopta para exponer su relato. Entre estas formas discursivas se encuentra el comentario, por el que el narrador, dejando a un lado la trama narrativa, da a los lectores una información, introduce una explicación, hace una confidencia o un comentario al servicio del desarrollo y recepción de su historia ${ }^{10}$.

A través de su punto de vista, manifestado de forma explícita en sus comentarios, el narrador expresa su juicio sobre un personaje en función de su sistema de valores y de su concepción del mundo. De esta forma configura la identidad narrativa del personaje: su carácter duradero a lo largo del relato. La identidad narrativa de los personajes permite al lector el acceso al mundo del relato, y a la vez le ofrecen una forma de vida posible, una posibilidad de existencia concreta. Es la identidad narrativa la que permite al lector apropiarse de la identidad del personaje para interpretarse a sí mismo, porque la figuración de uno mismo a través de la mediación de otro puede ser un medio auténtico de descubrirse a sí mismo ${ }^{11}$. Es el narrador quien guía al lector en esta elección o atracción hacia un personaje, mediante su punto de vista evaluativo y por un procedimiento de focalización, que permite al narrador hacer partícipe al lector de su información sobre el personaje ${ }^{12}$.

Es evidente que los comentarios explícitos del narrador son un instrumento valioso para este procedimiento, especialmente en la focalización interna, que da acceso a la interioridad de los personajes (Jn 2,17.24; $4,44 \ldots)$; también en la focalización externa, que corresponde con lo que vería un observador $(4,2 ; 5,9 \mathrm{~b} \ldots)$, y de nuevo especialmente en la focalización cero, que corresponde al plano que supera el marco temporal y espacial de la escena y dice más de lo que sabe ninguno de los personajes $(2,21.22 ; 7,39 \ldots)^{13}$. Por lo cual es pertinente estudiar la caracterización de Jesús que aparece en esos comentarios ${ }^{14}$.

10 Culpepper, “La narratologie”, 103-104.

11 Ricoeur, Historia y narratividad, 215-230.

12 Marguerat - Bourquin, Cómo leer los relatos, 95-125.

13 Ib., 118-121.

14 Para no alargar la extensión de este artículo, y porque la metodología para caracterizar un personaje es más conocida, no expondré aquí dicha metodología. Baste decir que, para descubrir la identidad de Jesús que el narrador quiere transmitir en sus notas, debemos fijarnos en los rasgos del ser, de acción y de relación que aparecen en ellas. Cf. VALLES, Teoría de la narrativa; ÁlAmo, "La caracterización”, 198-199; CAÑELLES, La construcción. 


\subsection{Definición de nota del narrador}

Fue Tenney el que distinguió, dentro de los comentarios del evangelio, los comentarios explícitos del narrador que no formaban parte de la trama narrativa, y que denominó, de forma original, footnotes ${ }^{15}$. Este autor las define como glosas o paréntesis que el escritor introduce en su historia para hacerla más clara, explicando la causa o motivo de alguna declaración para favorecer su comprensibilidad. El autor advierte sobre la dificultad de identificarlas, y también indica que es posible que recojan el estilo oral del autor del cuarto evangelio ${ }^{16}$. El trabajo de Tenney es la base de las definiciones de estas intervenciones directas del narrador en el cuarto evangelio. Pero es indudable que la aportación de los distintos especialistas para clarificar el concepto de nota del narrador constata la dificultad de identificarlas en el texto y evaluar si el comentario pertenece al hilo narrativo o no ${ }^{17}$. Todas las definiciones que se han dado siguiendo el criterio del contenido o la función que realizan en el relato no han logrado salvar esa dificultad.

Para salvar esta dificultad se puede recurrir a las modernas teorías de la polifonía y de la enunciación del relato, que proporcionan un criterio eficaz para identificar y definir verdaderamente el concepto de nota.

Esto es posible y pertinente, porque el método narrativo estudia tanto el contenido del relato como su enunciación, es decir, "cómo" es contado. La función de informar no es exclusiva del contenido del texto, sino, sobre todo, del enunciado. Esto hace que se tenga que estudiar la retórica narrativa del texto, el dispositivo mediante el cual un narrador enuncia la historia ${ }^{18}$.

El punto de vista del autor se transmite a través de la utilización de distintos mecanismos lingüísticos y procedimientos, entre los que destaca el de la polifonía ${ }^{19}$. La teoría polifónica de la enunciación considera que, en gran parte de los enunciados pueden rastrearse voces distintas y puntos de vista diferentes que se esconden detrás de las palabras que se escuchan en el texto. Estas voces del relato tienen una finalidad persuasiva, que no es otra que la de intentar atraer al lector hacia el criterio y la visión de las cosas del

\footnotetext{
5 TEnNEY, "The Footnotes".

16 Ib., 350-351.

17 Cf. nota 2.

18 Marguerat - Bourquin, Cómo leer los relatos, 39.

19 Escribano Hernández, Las voces del texto, 8-10.
} 
narrador, de manera que llegue a las mismas conclusiones que él ${ }^{20}$. Teniendo en cuenta esto, el primer criterio de identificación de una nota es que aparezca en la voz del narrador y no en otros personajes ${ }^{21}$. Pero este criterio por sí solo no es suficiente. La teoría de la enunciación también permite distinguir voces en el relato: el hablante, el locutor, el enunciador. De esta manera, se pueden definir las notas del narrador como los enunciados en los que el locutor aparece como enunciador de su propio relato. En ellos, el narrador aparece desdoblado, presentándose en dos momentos distintos: en uno como constructor del texto, en otro como comentarista que lo aclara, lo completa o justifica. De esta forma, en sus notas, el narrador se distancia de su propio discurso juzgándolo, pues lo juzga al mismo tiempo que lo emite. Cuando el narrador aparece como enunciador de su propio discurso, su enunciado presenta una serie de características que lo constituyen como enunciado parentético:

- Aparece insertado en otro enunciado.

- Diferenciados en lo entonativo.

- Sin conexión sintáctica entre ellos.

- Mantienen una relación semántica variable ${ }^{22}$.

Estas características parentéticas permiten caracterizar una nota como una información adicional, no pretendida originariamente, que aparece interrumpiendo una secuencia narrativa y sintáctica y que no debe ser considerada como secundaria ${ }^{23}$. Estas características reflejan rasgos propios del lenguaje oral en la escritura, acercando así el texto escrito a un registro coloquial, directo, próximo al lector ${ }^{24}$.

Partiendo de estas aportaciones podemos definir las notas del narrador como el enunciado parentético que interrumpe la línea del discurso narrativo en el que el narrador aparece como comentador de su propio discurso, sin ninguna relación sintáctica con el enunciado comentado y

$20 \mathrm{lb} ., 47$. Esto es lo que busca el evangelista: persuadir a sus lectores para que crean en Jesús (cf. Jn 20,31). La profesora Asunción Escribano Hernández señala otros recursos lingüísticos utilizados en la literatura, que, aunque no son objeto de nuestro estudio, también se pueden rastrear en el cuarto evangelio: la cita de autoridad $(7,37-38)$, el tópico de la mayoría $(8,33)$, la diafonía $(8,54)$, la negación polémica $(18,36)$ o la ironía $(3,10)$.

${ }^{21}$ No entran en el ámbito de nuestro estudio las notas o comentarios que aparecen en labios de Jesús, como por ejemplo Jn 4,23.

22 Fuentes Rodríguez, “Estructuras”, 159.

23 Fuentes Rodríguez, "Lo oral en lo escrito", 231.

24 Ib., 244. 
que posee una función macroestructural en la que el narrador completa una información aclarándola, comentándola, especificándola o añadiendo un dato que permite al lector interpretar adecuadamente la información recibida.

Las notas mantienen una relación semántica con el enunciado comentado, aunque no sea sintáctica. Por lo cual, para estudiar la nota, se debe tener en cuenta también el contenido del enunciado comentado. Estos dos enunciados forman lo que se denomina una estructura parentética, que consiste en la inserción de dos enunciados en uno, sin nexo entre ellos, marcada por un determinado esquema melódico. A su vez supone una interrupción sintáctica cuya cohesión se establece por el tema ${ }^{25}$. Son comentarios que hace el hablante sobre su propio discurso, interpretándolo a la vez que lo emite. La disposición entonativa del enunciado parentético muestra la intencionalidad del hablante de presentarlo como información de segundo plano y como comentario de lo previo, mostrando una actitud reflexiva, muy cercana a la actividad reformulativa ${ }^{26}$.

Estas aportaciones de la teoría lingüística de la enunciación confirman la intuición de que este material parentético es relevante para la interpretación de la obra, porque es un material con un rendimiento informativo y argumental notable. El narrador, al resaltar lo dicho por medio de su intervención directa, capta la atención del oyente sobre el enunciado mismo y el elemento comentado, haciendo aparecer su comentario como algo recordado en el momento, que, aunque se suma a lo anterior, parece más importante y se destaca en su presentación ${ }^{27}$. En el campo del estudio del cuarto evangelio, esta caracterización de las notas del narrador es muy similar a la descripción que hace Zumstein del fenómeno de relecturas en el relato joánico. Estas relecturas no tienen como función completar vacíos en la trama narrativa, sino profundizar la reflexión teológica del texto comentado. Entre ellos se instala una relación de sentido precisado por el comentario. En la relectura, el segundo texto, lo que en nuestro caso sería la nota del narrador, no invalida el valor del primer enunciado, sino que, reconociéndolo, hace posible el nacimiento de un sentido superior escondido en él ${ }^{28}$.

25 Ib., 243.

26 Fuentes Rodríguez, “Parentéticos”, 82.

$27 \mathrm{Ib} ., 83$.

28 ZUMSTEIN, “Processus de relecture", 42-43. 


\section{Las notas cristológicas en la estructura general del relato}

En este apartado estudiaremos tres notas cristológicas relacionadas entre sí y que ocupan un lugar estratégico dentro del relato, de tal modo que lo estructuran (Jn 1,17-18; 12,41; 20,30-31). En un primer momento se analiza cada una de las notas para mostrar cómo caracterizan a Jesús y qué papel juegan en la trama del relato; en segundo lugar se expone cómo se relacionan entre sí.

\subsection{La nota de Jn 1,17-18}

Las primeras notas cristológicas que encontramos en el relato joánico se sitúan al final del prólogo (vv. 17-18). Estas dos notas juegan un papel fundamental en la intratextualidad de todo el relato, ya que crean un puente entre el prólogo y la narración propiamente dicha ${ }^{29}$. Por su posición comentan todo el prólogo, pero especialmente los vv. 14 y 16, es decir, la encarnación del Logos y los beneficios que los hombres reciben de él ${ }^{30}$.

Jn 1,17: Hóti ho nómos dià Mōuséōs edóthē hē járis kái alētheia dià Ièsoû Jpistoû egéneto, forma una estructura parentética con los vv. 14 y 16. Los tres versículos aparecen conectados por las expresiones plērēs járitos kái alētheías, járin antì járitos $\cdot y$ hē járis kài hē alètheia. En el v. 14 se dice que el Logos encarnado ha recibido la plenitud de la gracia y la verdad; la nota permite al lector identificar al Logos con Jesús Mesías ${ }^{31}$ como la fuente de la gracia y la verdad que los miembros de la comunidad han recibido como gracia sobre gracia ${ }^{32}$. Este es el fin primordial y básico de esta nota, que permitirá al lector leer correctamente el resto de la historia. Jesús es caracterizado como Mesías que hace presente y actualiza la gracia y la verdad, términos que se hacen eco de los capítulos 33-34 del Éxodo ${ }^{33}$."Gracia" y "verdad" aparecen como paralelos a los términos que definen el nombre de Yahvé en Ex 34,6, pues son las traducciones de hésed y 'ĕmet.

29 ZUMSTEIN, “Le prologue”, 228.

30 VIDAL, Los escritos originales, 384-391.

31 Iēsoû Jristoû puede ser traducido por el nombre propio "Jesucristo", pero también podemos traducir literalmente por "Jesús Mesías" como aposición, ya que el mismo narrador nos indicará más adelante que así lo debe entender el lector $(1,41 ; 4,25)$.

32 MAC LEOD, "The Benefits of the Incarnation”, 183.

33 Maronde, “Moses in the Gospel”, 26. 
Hésed es la ternura o la misericordia de Dios al elegir a Israel y su expresión a lo largo de la Alianza. 'Ёmet es la fidelidad de Dios a esas promesas y a su elección ${ }^{34}$; ambas se realizan en Jesús, que queda caracterizado como el auténtico cumplimiento de las esperanzas de una redención escatológica; en él ocurre el verdadero y adecuado cumplimiento de las profecías y las esperanzas bíblicas, aquel en quien Israel debería hallar la expresión definitiva de la fidelidad y del designio redentor de $\operatorname{Dios}^{35}$.

Pero el lector aún puede albergar una duda: ¿cómo es posible que Jesús realice la "gracia" y la "verdad"? Para resolver esta cuestión, el narrador añade una digresión que sirve de fundamento al enunciado del v. 17 y desvela otro aspecto fundamental de la identidad de Jesús: su divinidad y su relación única con Dios, lo cual fundamenta la superioridad y singularidad de su revelación.

Theòn oudeis heōraken pōpote monogenēs theòs ho ōn eis tòv kólpon toû patròs ekeînos exēgēsato ${ }^{36}$.

Este v. 18 se relaciona con la nota anterior por la alusión evidente al libro del Éxodo (cap. 33). También se relaciona con el v. 14, pues el Logos encarnado ha recibido la gloria de monogenoûs. De esta forma, el lector puede concluir que Jesús Mesías es el Logos encarnado (v. 17) y también el Unigénito; los tres versículos hablan del mismo personaje. Pero la nota añade algo más: Jesús Mesías Unigénito es Dios. De esta forma, este versículo queda vinculado con el primero del Prólogo y forma con él una inclusión por los térmi$\operatorname{nos}^{37}$. Los vv. 1-2.14.17-18 están relacionados entre sí y vinculan las figuras del Logos preexistente, el Logos encarnado y Jesús. Los vv. 1-2 hablan de la relación entre el Logos y Dios, que en el v. 14 aparece en términos de padre e hijo. En el v. 17 se identifica ese Logos encarnado con Jesús, que no ha perdido su condición divina y su relación con Dios, como indica la nota del v. 18.

34 Brown, El evangelio I-XII, 208-209.

35 Hurtado, Señor Jesucristo, 410, 412.

${ }^{36}$ En el v. 18 aparece un problema textual significativo. Son posibles varias lecturas, cf. Metzger, A Textual Commentary, 169-170. Schnackenburg opina que cualquiera de las lecturas está en armonía con la imagen de Cristo que se irradia en el evangelio, por lo que adoptar una u otra no cambia nada sustancialmente (SCHNACKENBURG, El evangelio I, 293-294). Por lo que, atendiendo al peso de los testigos y la referencia de Jn 1,1, debemos preferir la lectura monogenēs Theòs, en la que Theòs es una aposición de monogenēs. De la misma opinión es Léon-Dufour (LÉon-Dufour, Lectura del evangelio I, 105.).

37 Painter, "The Prologue", 59. También son de la misma opinión J. Staley (Staley, “The Structure of John's Prologue") y Culpepeer (CULPEPEER, "The Pivot of John's Prologue"). 
La nota comienza con una afirmación universal: Theòn oudeìs heōraken pōpote. Es una afirmación sobre Dios mismo que está recogida en la secuencia del Éxodo en la que Dios se reveló a Moisés (Ex 33,20-23). Ahora, un nuevo conocimiento de Dios se ha producido, como ha confesado el narrador en 1,14: kài etheasámetha tēn dóxan autoû dóxan òs monogenoûs parà Patrós. Este conocimiento se ha producido gracias a alguien que es igual a Dios y además vive en intimidad con él, que el lector identifica con Jesús: monogenēs theòs ho ōn eis tòv kólpon toû patròs. El término monogenē $s^{38}$, con un lenguaje muy próximo a las relaciones familiares, nos habla de una relación única y singular, habla de amor y comunión. Jesús, al ocupar ese lugar en relación con el Padre, conoce sus secretos y comparte su misma naturaleza divina ${ }^{39}$. Al poseer esa intimidad está cualificado para darlo a conocer ${ }^{40}$. Por lo cual la expresión ho ōn eis tòv kólpon toû patròs posee una función informativa significativa para todo lo que sigue: Jesús Mesías Unigénito no ha perdido su unión con Dios Padre en su encarnación, en su vida terrena continúa unido a Dios, idea que quedará manifiesta a lo largo de la narración $(12,45 ; 14,7-11)$.

La nota concluye exponiendo la misión del Unigénito en el mundo: exēgēsato ${ }^{41}$. Ha venido a "relatar", "exponer", a "dar a conocer" a Dios.

${ }^{38}$ En principio, monogenēs no se refiere explícitamente a un hijo, pero por el contexto y el uso podemos entenderlo en el ámbito de las relaciones paterno-filiales, sobre todo en el v. 18, en el que "Dios" y "Padre" aparecen identificados.

${ }^{39}$ Algunos autores ven en la expresión ho ōn eis tòv kólpon toû Patròs una alusión a la vuelta de Jesús al Padre (13,1-2) tras su pasión y su resurrección, formando así una inclusión con 1,1. Esta opinión es adecuada, pero no es la única lectura posible. Si tenemos en cuenta la naturaleza paratextual del prólogo, podemos deducir que este ha sido elaborado y leído a partir del relato al que antecede y tiene como fin dar las claves de interpretación adecuadas al lector a la hora de enfrentarse con la narración (Alvarado, Paratexto, 54-55).

40 MAC LEOD, “The Benefits of the Incarnation", 191. Esta idea era familiar a los lectores del evangelio de Juan, que conocen las relaciones entre el padre y el hijo dentro de las familias. El hijo debía ser como su padre, algo testimoniado también en la Escritura (Eclo 30,4; 44,10-11). La íntima unión entre el padre y el hijo es el fundamento de la estructura familiar de la antigüedad. De modo análogo, la íntima unión entre Dios y Jesús asegura la revelación del relato (GuIJARro, Fidelidades en conflicto, 139).

41 Léon-Dufour traduce exēgēsato del v. 18 como "ha contado", una traducción más literal que la de "revelar", en el sentido técnico de revelar misterios divinos

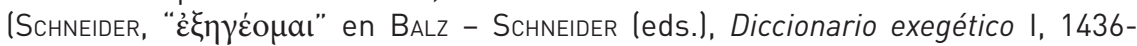
1437), pero que sí coincide con la finalidad señalada para este versículo por el narrador, porque lo que viene a continuación es la puesta por escrito de lo que Jesús “ha contado", es decir, un relato (LÉon-Dufour, Lectura del evangelio I, 110-111). 
Con sus palabras, Jesús se convierte en la interpretación de Dios en el mundo, su testigo $(3,11.32 ; 5,37 ; 8,38)$. Esta nota del narrador revela la plena dignidad divina y la plena capacidad de revelación de Jesús. El uso de este verbo hará caer en la cuenta aún más al lector de la relevancia de las palabras de Jesús en la narración y entender las afirmaciones tan radicales sobre su propia palabra $(5,24 ; 6,63)$.

También el "haber visto" juega un papel importante en la trama del evangelio de Juan. Desde este punto de vista, el narrador, al presentar a Jesús como el testigo de Dios, hace que su testimonio genere un relato "de Jesús sobre Dios" que permite a los que han visto a Jesús ver a Dios. Esto permite leer la nota de 1,18 como el título de la historia de Jesús Mesías, interpretación lograda de $\operatorname{Dios}^{42}$. Este se revela de forma última y plena en la historia del hombre Jesús, se da una cristologización radical de la cuestión de Dios: Jesús es singular por su relación única con Dios e, inversamente, Dios no tiene otra manifestación para los hombres que no sea Jesús ${ }^{43}$. No se puede encontrar a Dios sino en Jesús, y Jesús no puede ser encontrado sino en el evangelio en cuanto Palabra de Dios.

Por medio de estas dos notas, el narrador une la afirmación mesiánica y la de la filiación divina antes de comenzar su relato propiamente dicho. En ellas se refiere tanto a las acciones como a las palabras de Jesús. Por sus acciones y en sus acciones, Jesús Mesías hace presente la gracia y verdad de Dios para los hombres. Por sus palabras da a conocer a Dios mismo a los hombres. Esto es posible porque Jesús mantiene una relación única con Dios, que le hace a él mismo divino y coloca su persona y su revelación por encima de cualquier otra persona o revelaciones anteriores.

\subsection{La nota de Jn 12,41}

Jn 12,41 aparece dentro de la perícopa 12,37-41, donde encontramos distintas notas del narrador (12,38-40), y forman un verdadero epílogo a la primera parte de todo el relato. En estas notas se presenta el fracaso del ministerio de Jesús como el cumplimiento de la Escritura. La nota que nos ocupa se añade para manifestar la autoridad del testigo que ha sido citado

42 ZUMSTEIN, El evangelio (1-12), 83. El título es ya una clave interpretativa del texto. Sus funciones son las de identificar la obra, designar su contenido y atraer al público (Alvarado, Paratexto, 47-50). Hay que tener en cuenta que no es un título estrictamente hablando, pero cumple estas tres funciones, sobre todo las dos últimas.

$43 \mathrm{lb} ., 83$. 
en las anteriores: Isaías, del cual se afirma que vio la gloria de Jesús ${ }^{44}$. Jn 12,41 es la base de las dos anteriores y comenta ambas, lo cual hace que el lector descubra el rechazo de Jesús como plan de Dios.

Taûta eîpen Isaîas hóti eîden tēn dóxan autoû, kài elálēsen perì autôิ $(12,41)$ interpreta la teofanía del Templo del libro de Isaías (Is 6,1-10) en sentido cristológico. Para el narrador, Isaías no vio realmente a Dios (Is 6,5 LXX), sino la gloria de Jesús, y por eso su escrito se convierte en un testimonio acerca de Jesús. De esta forma, el narrador refuerza su propia afirmación de Jn 1,18: solo el Hijo Unigénito ha visto al Padre, y solo él le ha dado a conocer. Únicamente Jesús puede hablar del Padre y revelarlo. Isaías ha realizado esa misma misión no respecto a Dios, sino respecto a Jesús, el Hijo Unigénito que está en su seno.

Isaías ha visto la gloria de Jesús, la que le era propia (Jn 1,1-2) y tenía junto a su Padre antes de la creación del mundo (17,5). Así, el lector entiende que se está hablando de la preexistencia de Jesús y de su divini$\operatorname{dad}^{45}$. El profeta vio la condición filial y divina de Jesús, que ahora se manifiesta en su carne $(1,14)$ y que se revela por medio de sus signos y palabras, algo que los discípulos han contemplado y les ha llevado a la fe $(2,22)$. Por tanto, para Juan, Isaías ha hablado sobre Jesús y su misión salvífica, que está realizando como Hijo Unigénito, como profeta que, al ser enviado al mundo, ha tomado la forma de Siervo, que ha sido rechazado y que se manifiesta definitivamente glorioso en la cruz ${ }^{46}$.

El narrador recoge en esta nota una idea similar a la que expresa Jesús en su enfrentamiento ante los judíos en Jn 8. Allí utilizó la figura de Abrahán para legitimar su identidad y su autoridad $(8,56)$. El relato sitúa a Abrahán, como a Isaías, en la perspectiva de la promesa ${ }^{47}$. Jesús afirma que el patriarca vio su día y se alegró, entrelazando en esta afirmación dos tradiciones distintas. En primer lugar, se refiere al regocijo de Abrahán ante la acción de Dios por el don de un hijo (Gn 17,17-19; 18,9-15; 21,6), y, en segundo lugar, a la visión del tiempo mesiánico, que se refiere a la hora de la manifestación última de la gloria del Hijo, es decir, a la plena realidad divina.

44 Zumstein, El Evangelio (1-12), 537.

45 Schnackenburg, El evangelio II, 513.

46 Esta lectura se sostiene por las múltiples uniones que existen entre el Siervo y las secuencias anteriores del relato: en Is 52,13 se habla de la exaltación y glorificación delSiervo, que son aplicadasa Jesús en Jn3,16;8,28; 12,16.23.32.33.34.41.43. Cuando habla de su gloria, se está refiriendo a la gloria del Hijo de Dios, que se manifestó como el Siervo de Dios al ser exaltado y glorificado (SCACEWATER, "The Predictive Nature", 140).

47 Zumstein, El evangelio (1-12), 398-399. 
También aquí aparece la idea de Jesús como el Dios Unigénito, el Hijo de Dios, que es el cumplimiento del hijo dado a Abrahán, que manifestará la gloria definitiva de Dios y que, en el evangelio de Juan, ocurre en la hora de la cruz.

\subsection{La nota de Jn 20,30-31}

Estos dos versículos pueden ser leídos unidos al ciclo pascual como un comentario significativo a Jn 20,29. En este último, Jesús proclama dichosos a aquellos que crean sin ver. Ahora, el narrador invita a sus lectores a sumarse a este grupo "de los que no han visto" por medio de la lectura de su relato. Pero es indudable que estos versículos poseen un carácter conclusivo de todo el relato, ya que el término "signo" remite al lector a la primera parte de su historia. Por lo cual estos versículos deben leerse siempre en este doble nivel: como conclusión del ciclo pascual y a la vez, de todo el relato ${ }^{48}$.

${ }^{30}$ Pollà mèn oûn kài álla sēmeîa epoiésen ho lēsoûs enōpiov tōn mathētōn [autoû] hà ouk éstin gegramména en tō biblío toútōo ${ }^{11}$ taûta dè gégraptai hína pisteúéte hóti lēsoûs estin ho Jristòs ho Yiòs toû Theoû, kài hína pisteúontes zōēn ejēte en tō onómati autoû) (Jn 20,30-31)

Tal y como aparecen en el texto, estos dos versículos interrumpen la narración del relato de Jn 20,29, que continua en 21,149. La nota tiene las características de una conclusión o un epílogo. El epílogo es un enunciado que expone una situación posterior al desarrollo propiamente dicho del relato y que cumple las mismas funciones que un prólogo: informativa y persuasiva $^{50}$. El narrador cumple perfectamente ambas funciones. Jn 20,30

48 ZUMSTEIn, El evangelio (13-21), 373-374.

49 La crítica se divide en distintas posturas en lo que concierne al origen de estos versículos. Algunos les consideran la conclusión de una hipotética fuente lla fuente de los signos). Otra postura prefiere considerarlos como una composición redaccional (Schnelle). Por último, otras posturas más recientes defienden la autoría del propio evangelista, ya sean la conclusión del ciclo pascual (Hoskyns, 0’Day) o como parte de un epílogo más amplío (Thyen, Overbeck) que comenzaría en 20,30 y acabaría en 21,35 . Yo considero que estos versículos pertenecerían a la Fuente de los Signos (hipótesis, a mi juicio, bastante sólida). El autor ha utilizado esta fuente con mucha libertad y ha colocado material de esta fuente como notas del narrador, por ejemplo 2,$11 ; 4,54$. Por lo cual no es extraño que, al final del evangelio, la utilice para concluir su relato. Para ver un análisis sintético de las distintas opciones, cf. ZuMstein, El evangelio (13-21), 295.

50 Zumstein, “Processus de relecture”,41; Alvarado, Paratexto, 55. 
informa al lector sobre la actividad de Jesús y el carácter selectivo de las obras que han sido recogidas en el libro; 20,31 informa sobre la finalidad del libro, y quiere persuadir al lector para que, por medio de su lectura, crea en Jesús y reconfigure su vida como creyente.

El narrador caracteriza la actividad de Jesús como sēmeîa epoíêsen ho Ièsoûs, e informa al lector de que su relato no es exhaustivo. Siempre ha llamado la atención esta caracterización de la actividad de Jesús, pues el término "signo" apareció por última vez en el cap. 12, y hasta ese capítulo solo se usó para designar los milagros realizados por Jesús. ¿Tiene aquí el mismo significado? G. Van Belle ha dedicado un artículo a estudiar el significado de sēmeîa en este versículo. El autor repasa las distintas hipótesis que se plantean a la hora de identificar su significado ${ }^{51}$. Se ofrecen cuatro hipótesis con diferentes matices: el término se referiría a los milagros narrados en Jn 1-11, o bien solo a los relatos de las apariciones en Jn 20, o se refiere tanto a los milagros como a las apariciones, o, por último, al contenido del evangelio entero ${ }^{52}$. Esta última interpretación parece la más acertada, y la que recoge las mejores aportaciones de las demás. Esto invita a considerar el relato, el libro en sí mismo, como un nuevo signo. La insistencia del narrador en el carácter escrito de la revelación (gegramména, gégraptai) y el pronombre personal taûta, que señala los signos recogidos en el libro, conducen a pensar que el relato escrito se presenta como un sustituto de los signos que realizó Jesús en su vida terrena y de su actividad reveladora. De esta forma, los lectores tienen acceso a la vida eterna a través de sus páginas ${ }^{53}$. Los lectores son invitados a hacer la misma experiencia que los discípulos en Caná, en la que vieron su gloria $(2,11 ; 1,14)$, su identidad como Mesías e Hijo de Dios (1,17-18). El campo de la historia total de Jesús delante de los discípulos se restringe ahora al campo del relato, que sirve para construir la fe de los discípulos ${ }^{54}$.

En resumen, consideramos que el narrador, en la primera parte de su nota $(20,30)$, tomó el término "signo" de su fuente, pero amplió su significado enormemente, con el objeto de utilizarlo para referirse a toda la actividad reveladora de Jesús, su vida entera, y que ahora queda recogida por escrito. Convirtió el relato en un nuevo "signo" que muestra la gloria de su identidad, para que los lectores accedan a la fe y al conocimiento de Jesús.

51 Cf. Van Belle, “The Meaning”.

52 lb., 301.

53 Ib., 309.

54 Sevrin, “Le deux finales”, 242. 


\subsection{La relación entre las tres notas cristológicas}

Las tres notas estudiadas comparten algunas características que las relacionan entre sí. Todas se refieren a Jesús, lo cual permite considerar que su identidad es el interés principal de la obra, ya que, por su carácter paratextual, están focalizadas dentro del relato. Las tres ocupan una posición conclusiva y a la vez dan paso a lo que sigue. Jn 1,17-18 es la conclusión del prólogo, y como título del relato da paso a la narración en sí misma; 12,41 es la conclusión de la vida pública de Jesús, que queda respaldada por la autoridad de la Escritura y da paso al relato de la pasión, en la que se cumplirá la muerte anunciada en su ministerio; por último, 20,30-31 concluye tanto el relato de la pasión como el de las apariciones de Jesús, pero, tal como se encuentra en el texto final, da paso al epílogo del cap. 21, en el que se presenta y legitima, en el tiempo del lector, al discípulo que da testimonio y avala el relato. Así se da paso a la lectura y apropiación del relato por parte del lector.

La nota de Jn 1,17-18 coincide en la forma de caracterizar a Jesús que encontramos en la nota que concluye el relato $(20,30-31)^{55}$. En ella, el lector vuelve a encontrar la caracterización inicial de Jesús como Mesías y como Hijo de Dios, por lo que el lector entiende perfectamente que la narración que comenzó con la presentación de este personaje, en el final del prólogo, ha llegado a su fin. El lector es invitado a hacer el mismo reconocimiento al que llega Marta al final del ministerio público de Jesús $(11,27)$, que no ha quedado refutado por la pasión, sino confirmado.

Jn 1,17-18 se relaciona con 12,37-41. Ambas notas se refieren a la visión de Dios. En Jn 1,18 se dice que nadie ha visto a Dios, salvo el Dios Unigénito, lo cual permite al narrador interpretar Is 6,5 como una visión, no de Dios, sino de la gloria de Jesús, Dios Unigénito. Jesús aparece como el único revelador de Dios, e Isaías como el testigo que ha visto la gloria de Jesús y lo ha testimoniado en su mensaje profético, al igual que Jesús nos ha contado la verdadera identidad de Dios en el ministerio terreno, que ahora queda confirmado como voluntad de Dios. Implícitamente, Jn 12,41 se relaciona con 1, 17, donde Jesús es caracterizado como Mesías, Hijo de Dios, pues justamente eso es lo que contempló Isaías, su gloria: la manifestación de su verdadera identidad.

55 Considero, con la mayoría de estudiosos, que el capítulo 21 es un epílogo de la narración, que, por sus características paratextuales, nos permiten hablar de Jn 20,30-31 como conclusión propiamente dicha del relato. Aguado, Paratexto, 55; ZUMSTEIN, “Le processus”, 169. 
Por último, Jn 12,37-41 está relacionado con 20,30-31. En las dos notas, los signos que realizaba Jesús son el objeto de la reflexión del narrador, y en ambos casos se relacionan con el tema de la fe. En el cap. 12, pese a los signos, los judíos no han creído en Jesús. Por el contrario, en 20,30-31, la transmisión de esos mismos signos sirve para creer en Jesús, contando con la garantía de la revelación dada tanto en la Escritura como en el relato que los recoge.

Estas tres notas cristológicas tienen en común y desarrollan una de las tramas narrativas fundamentales del cuarto evangelio: el "ver", un ver que se convierte en relato. En Jn 1,18 se afirma que a Dios nadie lo ha visto nunca, es Jesús, el Dios Unigénito, el que lo ha contado. Es decir, la visión que Jesús posee de Dios se convierte en un relato de Jesús sobre Dios, en eso consistió su vida pública. De la misma manera, Isaías, según el narrador del cuarto evangelio, ha visto la gloria de Jesús $(12,41)$. De esta forma, su testimonio, la Escritura, es un relato de Isaías sobre Jesús, en el que se testimonia que el Hijo de Dios se ha manifestado como Siervo obediente ante los hombres y ha sido rechazado por ellos. En la nota final de 20,30-31, Jesús ya no es visible a los ojos de los lectores; en cambio, se les presenta un relato que ha nacido también de un "ver". En efecto, en 19,35, el narrador señala, por medio de una nota, que el discípulo amado ha visto a Jesús en la cruz y todas las circunstancias que rodearon su muerte. Este discípulo es el que da testimonio, y de su testimonio nace el relato que da acceso a la fe y a la vida eterna. Este nuevo relato, ahora escrito, es fiable para el lector, ya que el garante del relato $(19,35)$ ocupa la misma posición respecto a Jesús que este ocupaba respecto al Padre. Del mismo modo que Jesús es el único que ha visto a Dios porque está en el seno del Padre, y sus palabras constituyen un testimonio del Padre $(3,11)$, el discípulo amado ha visto a Jesús en el momento más crítico de su vida $(19,35)$ y da testimonio de él $(21,24)$, y su testimonio, su relato, es verdadero, porque estaba en el seno de Jesús $(13,23)^{56}$. Desde el punto de vista de las notas del narrador, Jesús es el testigo de Dios, su testimonio genera un relato "de Jesús sobre Dios" que permite a los que han visto a Jesús ver a Dios. Cuando Jesús no está y no es accesible por la visión, el testimonio del discípulo amado genera un relato "de Jesús sobre Jesús", que ocupa el lugar del propio Jesús y que por la fe otorga los mismos beneficios (20,30-31) que su presencia $(2,11)$.

Son estas tres notas referidas a Jesús como Mesías e Hijo de Dios, revelación única de Dios, las que determinan la estructura y el objetivo del relato: Jesús ha venido a mostrarnos la identidad de Dios Padre, manifestando su gloria de Hijo Unigénito que, tras ser rechazado, siguiendo el plan de

56 ZumsteIN, “La naissance”, 375. 
Dios, se va a manifestar de forma definitiva en la cruz. Tras ello, la revelación de Jesús y, por tanto, de Dios Padre continúa en el relato joánico. Estas notas nos invitan a considerar el evangelio como una verdadera narración sobre la identidad de Jesús y que, para darla a conocer, el autor adoptó un género literario determinado: el esquema de vidas antiguas.

\section{El cuarto evangelio, una "vida antigua" de Jesús}

En los últimos años se ha explorado la relación entre los evangelios con las biografías helenísticas. Se puede comprobar que los evangelios, también el de Juan, pese a sus diferencias con los sinópticos, adoptan la misma estructura y responden a fines muy similares ${ }^{57}$.

\subsection{Características de las "vidas antiguas"}

El profesor Santiago Guijarro ofrece una excelente síntesis sobre las características, estructura y finalidad del género literario de las vidas antiguas y su similitud con los evangelios.

Una vida helenística es un tipo particular de relato que se sitúa entre la historia y el encomio. Se diferencia de la historia en que se centra en un solo personaje, y del encomio, en que no solo se centra en ensalzar el honor del personaje, sino que también se ocupa de los acontecimientos históricos que le rodearon para crear su relato.

Las vidas antiguas poseen tres partes bien diferenciadas, con distintas finalidades cada una:

a) La parte que trata de los orígenes del personaje recoge la infancia y la juventud, para poner de manifiesto su honor adscrito, el que le corresponde por su pertenencia familiar, por su lugar de nacimiento o por su educación.

b) La parte que se dedica a su vida pública relata las acciones y enseñanzas del protagonista. En ella se pretende mostrar su carácter moral. Puede tener una disposición cronológica o temática ${ }^{58}$.

c) En la última parte se narran las circunstancias y el motivo de la muerte del personaje.

\footnotetext{
57 Guijarro, Los cuatro evangelios, 58-60.

58 En las biografías judías, en esta sección se insistía en las estrechas relaciones del protagonista con Dios.
} 
La finalidad de estos relatos es provocar la alabanza y el reconocimiento del protagonista, proporcionar al lector un modelo de vida; a la vez que conserva una tradición, mantiene la enseñanza del personaje y lo defiende de posibles ataques y desacreditaciones. En los evangelios, esta finalidad es específicamente religiosa; buscan provocar y fortalecer la fe de otros creyentes, dando testimonio de una experiencia que había cambiado radicalmente sus vidas (Jn 20,30-31). Sus autores recogen una tradición anterior, transmitida fielmente, para preservar y honrar la memoria de Jesús, y organizan su contenido según el esquema tradicional del anuncio cristiano $^{59}$.

El evangelio de Juan responde a este esquema. Las notas del narrador, que hemos estudiado, ocupan los lugares clave que delimitan las partes principales de una vida antigua: al final del prólogo (Jn 1,18), al final de la vida pública de Jesús $(12,38)$ y antes de su pasión (12,38-41) y en la primera conclusión del relato evangélico $(20,30-31)^{60}$.

Pero el narrador no solo estructura el relato por medio de las notas cristológicas. A lo largo de la trama narrativa, otras notas cristológicas ayudan a avanzar la trama para guiar y centrar el interés del lector en distintos aspectos de la identidad de Jesús. De esta manera, el narrador contribuye, de una manera fundamental, a cumplir los fines típicos de las vidas antiguas.

\subsection{Los orígenes de Jesús en el cuarto evangelio}

Al colocar el verdadero origen de Jesús en forma de prólogo, es decir, fuera del tiempo de la historia del relato, el autor se ve obligado a introducir un título al final para poner en marcha el relato y que el lector tenga una información privilegiada sobre el protagonista de la narración que va a comenzar $^{61}$. Esta función la desarrollan las notas cristológicas de Jn 1,17-18,

59 GuIJARRo, Los cuatro evangelios, 58-60.

60 Consideramos Jn 21 un epílogo al relato del cuarto evangelio, por tanto supone la lectura de la narración a la que sirve de epílogo.

${ }^{61}$ Algo similar ocurre en el evangelio de Marcos. Este comienza con un título (Mc $1,1)$ en el que se recogen las mismas identificaciones para Jesús que en nuestras notas y se van confirmando a lo largo del relato $(8,29 ; 15,39)$. El profesor Santiago Guijarro ha mostrado de forma convincente la función de los primeros versículos del relato marcano: Marcos se sirvió de tradiciones relacionadas con el comienzo de la actividad de Jesús para revelar el origen de su honor adscrito: GuIJARRo, “ ¿Por qué comienza así el evangelio de Marcos?" También señala esta relación Dodd (DodD, Interpretación, 296). El autor del evangelio de Juan persigue el mismo fin y lo realiza utilizando una tradición propia, el himno tradicional, y tradiciones relacionadas con 
pues convierten el prólogo en la parte de las vidas antiguas donde se muestra el honor adscrito del protagonista del relato. En 1,17 se identifica al personaje, Jesús Mesías, con el Logos encarnado, cuyo honor se ha mencionado explícitamente en 1,14.

Myers ha mostrado cómo en el prólogo joánico aparecen "los lugares comunes" de las primeras partes de los encomios helenísticos: orígenes del personaje, su educación, sus hechos o acciones y comparaciones con otros personajes ${ }^{62}$. El origen de Jesús es único, su naturaleza es divina, aparece como la perfecta imagen de su Padre, con el que posee una relación exclusiva de intimidad, lo cual le concede una superioridad sobre todos los demás hombres (Jn 1,1.18). Esta información permite al lector contrarrestar las noticias deshonrosas que sobre el origen de Jesús se recogen en el relato $(1,46 ; 7,41-43 ; 8,48)$. El prólogo excluye cualquier tipo de educación formal, algo que será criticado en el cuerpo del relato por los oponentes de Jesús (7,14-15), ya que Jesús tiene acceso permanente, y toda la instrucción la recibe del Padre (5,19-30; 6,37-38; 7,16-17; 8,28; 10,37-38; $12,49.50)$, de esta forma se sustituye la educación formal del personaje por la referencia al lugar que ocupa junto al Padre $(1,18)$. Como actuación más sobresaliente de sus orígenes aparece su papel en la creación $(1,12-13)$, papel que sigue realizando tras su encarnación $(5,26)$. Por último, Jesús aparece comparado con otros personajes: Juan Bautista y Moisés, quedando reforzada su superioridad y su autoridad frente a ellos (1,6-7.17-18).

Podemos decir que el prólogo cumple con las tres funciones que Malbon atribuye a los comienzos de los evangelios: conectar al lector con el texto, relacionar el texto con otros textos y crear el mundo del relato.

\begin{abstract}
Juan Bautista (Jn 1,6-8.15), mostrando el honor adscrito de Jesús. J. Painter relaciona el comienzo del evangelio de Juan con el comienzo del evangelio de Marcos, pero lo reduce solo al papel asignado a Juan Bautista en el prólogo joánico. Yo creo que también en la nota del narrador se puede encontrar esa relación (PAINTER, "The Prologue", 43-44). La misma opinión ofrece Matera (MATERA, New Testament Christology, 216). Considero que el evangelio de Juan es una interpretación creativa de la tradición sobre Jesús, de la que buena parte es compartida con los sinópticos. La originalidad de Juan reside en la búsqueda del sentido profundo de las acciones y enseñanzas de Jesús desde la convicción de que es el Logos encarnado. Las relaciones del cuarto el evangelio con los sinópticos es compleja; adopto aquí la posición más ponderada, expresada por el profesor Guijarro: el autor del evangelio de Juan conoció los sinópticos, pero no los utiliza como referencia fundamental, pudiendo así componer un evangelio que integrase tradiciones distintas sobre Jesús (GuIJARRo, Los cuatro evangelios, 99, 527). Lo que no excluye que Juan utilizase el mismo esquema literario que adoptaron los sinópticos: el de las vidas helenísticas (lb., 57-60).
\end{abstract}

62 Myers, Characterizing Jesus, 61-69. 
Zumstein señala estas mismas funciones en el prólogo (interacción con el lector, relación de intertextualidad e intratextualidad), lo que confirma su papel como inicio de la bios de Jesús. Estas tres funciones se concentran en las notas de 1,17-18: identifican al protagonista del texto para el lector, se le relaciona con la revelación de Moisés recogida en la Ley (Escritura) y define el relato que sigue como el testimonio de Jesús sobre Dios ${ }^{63}$.

\subsection{El ministerio público de Jesús $\left(\right.$ Jn 1,19-12,41) ${ }^{64}$}

Las notas cristológicas continúan marcando la estructura del relato a lo largo de la segunda parte del evangelio, en la que se narra su ministerio público.

Parece claro que las notas de Jn 2,11 y 4,54 forman una inclusión que delimita la primera parte del ministerio público de Jesús $(1,19-4,54)$. Estas dos notas está unidas por su referencia y numeración a los signos de Jesús. En los episodios que comentan, Jesús está en Caná de Galilea $(4,46)$. Las dos notas tienen relación con el "ver" y "no ver" que ya hemos señalado: en la primera se dice que Jesús manifestó su gloria y que los discípulos creyeron en él: se entiende que vieron su gloria; la nota de 4,54 comenta que el funcionario público llega a la fe no porque ha visto un signo, sino porque ha obedecido la palabra de Jesús (4,50.53). Este recorrido de fe es justamente el que va proponer el evangelio al lector.

Las notas cristológicas de esta primera parte del ministerio público se centran en el acceso a la fe en Jesús y, por así decir, a mostrarnos un posible mapa geográfico de los lugares en los que arraigó esa fe ${ }^{65}$. Después de presentar la identidad de Jesús basándose en la fe tradicional recogida en las Escrituras (Jn 1,19-50), y tras escuchar la promesa de Jesús de "ver cosas mayores" $(1,51)$, el relato continúa con dos escenas programáticas que concluyen con sendas notas del narrador: el signo de Caná $(2,11)$ y el episodio en el Templo de Jerusalén $(2,22)$. Las dos notas muestran las dos formas distintas de alcanzar la fe en Jesús. En 2,11 la fe se alcanza al contemplar su

${ }_{63}$ Malbon, "Ending at the Beginning”, 175-184; Zumstein, "Le prologue”, 228.

${ }^{64}$ Colocamos el final del ministerio público en Jn 12,41, ya que 12,44-50 es una intervención de Jesús atemporal y deslocalizada (no hay ninguna referencia de tiempo y de lugar, ni a quién va dirigida); parece un monólogo de Jesús que viene a sintetizar su mensaje antes de entrar en la narración de la pasión.

65 No debemos olvidar que la opinión comúnmente aceptada entre los estudiosos del evangelio de Juan es que este, a la vez que narra la historia de Jesús, narra la historia de la comunidad. 
gloria de Mesías, Hijo de Dios; en cambio, en 2,22, la nota nos sitúa en el tiempo posterior a la resurrección, el tiempo del lector, donde a la fe se accede por el recuerdo y la fe en las palabras de la Escritura y del propio Jesús.

La nota de Jn 2,24-25 sirve de conclusión a estas dos escenas y abre el camino a nuevos desarrollos sobre la fe en Jesús. En el v. 24 se anota que Jesús no se fiaba de la fe de los que estaban en Jerusalén, una fe que nacía de haber visto los signos (no la gloria). Esta nota pone en guardia al lector frente a la ineficacia para acceder a la fe por la visión de signos, como quedará demostrado en 12,37. Las siguientes escenas se pueden entender como caminos que recorren distintos personajes para acceder a la fe que representan a los judíos, los samaritanos y los gentiles (Nicodemo, la samaritana y los samaritanos, el funcionario real). Al final de esta sección, el funcionario aparece como el modelo del creyente para el lector, que cree sin haber "visto signos".

Varias de las notas de esta primera parte aluden o citan explícitamente lugares geográficos o comentan situaciones que han ocurrido en lugares concretos (Jn 2,11, Caná; 2,24-25 comenta la fe que aparece en Jerusalén; 4,54, de nuevo Caná). Entre estas notas nos parecen muy significativas las de 4,4 y 4,44. En 4,4, el narrador presenta el paso de Jesús por Samaría como parte del plan de Dios ("tenía que pasar por Samaría"), y en 4,44 el narrador apunta que Jesús mismo había dicho que un profeta no es bien recibido en su patria, que en la trama del relato se refiere a Judea. Reuniendo todos los datos aportados en las notas se va dibujando el camino de la comunidad joánica propuesto por Brown y que generalmente es admitido en los estudios joánicos: origen en Judea, ingreso progresivo de elementos samaritanos e incorporación de elementos gentiles ${ }^{66}$.

Podemos concluir que, en esta primera parte de la vida pública de Jesús, las notas del narrador dirigen la atención de los lectores al acceso de la fe en Jesús. La fe nace al ver la gloria de Jesús, que se manifestaba en sus signos y que, tras su resurrección, nace al recordar las Escrituras y creer en la palabra de Jesús que aparecen en el relato joánico (Jn 4,54; 20,30-31).

En la segunda parte del ministerio público de Jesús (Jn 5,1-12,41), el rechazo a Jesús aparece desde el comienzo; antes solo se había insinuado en la trama y en algunas notas del narrador $(2,17 ; 4,1.3 .44)$, e irá in crescendo hasta el final de la sección. En esta secuencia, las notas cristológicas se centran en la muerte de Jesús y en su significado para los creyentes.

Al comienzo de la sección, el narrador presenta la decisión de los judíos de convertir su persecución a Jesús $(J n$ 5,16) en la decisión de matarlo,

${ }^{66}$ Cf. Brown, La comunidad del discípulo amado. 
pues se hacía sí mismo Hijo de Dios $(5,18)$. El lector ve confirmada esta decisión en la sentencia del Sanedrín (11,49-50), que es objeto de una importante nota del narrador (11,51-52). Entre estas notas, el narrador señala que la muerte de Jesús se producirá por la traición de uno sus íntimos, de lo cual Jesús es consciente $(6,64.71)$. Pero esa entrega solo se producirá cuando llegue su hora $(7,30 ; 8,20)$. De esta forma, el lector es consciente de que Jesús mantiene en todo momento su autoridad y su soberanía sobre su vida y su persona.

En esta misma sección, el narrador muestra las consecuencias beneficiosas de la muerte de Jesús para los creyentes: gracias a ella recibirán el don del Espíritu Santo $(\mathrm{Jn} 7,39)$ y se hará posible la reunión de todos los hijos dispersos en uno $(11,52)$, ya que esta muerte forma parte del plan divino (11,51). En una última nota (12,33), antes de las notas finales que cierran el ministerio público, el narrador relaciona la hora de Jesús, su glorificación y su exaltación (12,22.28-29.30-31) con la forma concreta de morir: la crucifixión. Así lo indica el término sèmaínō, que permitirá considerar su muerte como un signo que manifiesta su gloria, su verdadera identidad. Esta nota es una clave importantísima para descubrir el significado específico que el relato da a la muerte de Jesús.

En esta segunda parte del ministerio público vemos cómo la trama del relato va conduciendo a Jesús a un completo rechazo y a una muerte deshonrosa. Sin embargo, el lector puede descubrir, en las notas del narrador, otra visión de la muerte del protagonista: una muerte honrosa ${ }^{67}$. Esta es aquella muerte que aparece como beneficiosa para otros (Jn 7,39; 11,52), voluntaria $(6,64.71)$ y que cumple con la justicia, en nuestro caso con el plan de Dios $(11,51)$. La nota final de la sección $(12,41)$, al hacer balance del aparente fracaso de Jesús, señala paradójicamente que de esta forma se cumple el plan de Dios, y que en este fracaso se hace visible la manifestación más plena de su gloria, de su identidad como Hijo de Dios y Mesías $(12,41)$.

\subsection{Las notas del narrador en el relato de la pasión en el evangelio de Juan: "Todo se ha cumplido"}

En el relato de la pasión, todas las notas cristológicas muestran el cumplimiento en la muerte de Jesús, tanto de sus palabras (Jn 18,9.32) como de la Escritura $(19,24.36)$. De esta manera se confirma que el pro-

67 Myers, Characterizing Jesus, 165. 
tagonista muere libremente entregando la vida y cumpliéndose lo que el narrador ha ido señalando a lo largo de todo el relato. En 18,9 se cumplen las notas de $6,4.71$ y 17,12; Jn 18,32 es el cumplimiento de lo anotado en $5,16.18 ; 11,49-50$ y 12,33 ; Jn 19,24 se puede asociar al cumplimiento de 11,52 , y Jn 19,36-37 es la realización de lo anotado en 7,39; 11,52 y $12,32-33$.

Al finalizar el relato, el narrador se dirige al lector para invitarle a considerar la narración como un nuevo signo que conduce al descubrimiento de la verdadera identidad de Cristo y da acceso a la fe (20,30-31). El relato es designado como un biblío, una obra literaria que aparece como una verdadera y nueva Escritura, porque da acceso a la fe y contiene la revelación de Dios ${ }^{68}$. A partir de él, el lector tiene acceso a la fe y a la identidad de Jesús como la tuvieron los discípulos en su vida terrena. Un acceso que es posible por la relectura de las palabras y los actos de Jesús recogidos en el relato y que, junto con las Escrituras $(2,22 ; 12,16)$ que se presentan en el relato, permiten releer las palabras y las acciones de Jesús como un nuevo signo: el relato que se ha convertido en un libro de fe ${ }^{69}$.

Por todo ello, esta nota es relevante para considerar la naturaleza del relato como Escritura $^{70}$. La nota da testimonio del nacimiento de una nueva Escritura destinada a convertirse en el libro de la fe de los lectores junto con las antiguas Escrituras judías (Jn 2,22; 12,41) ${ }^{71}$. De esta forma, el lector puede llegar a descubrir la gloria de Dios y creer en él a través de su palabra, y no de la visión, como el funcionario público (4,21-22).

Jn 20,30-31 confirma el final del evangelio y la identidad de Jesús, que ha sido vindicado por Dios y que mantiene su relación con los creyentes por medio de la fe. Esta nota final persigue el mismo objetivo que el final de las vidas antiguas: convencer y persuadir a sus lectores u oyentes de que la versión que acaba de leer es la verdadera, entre otras opciones y versiones de la información sobre el personaje, con una función didáctica para que su audiencia imite al héroe del relato ${ }^{72}$.

68 Zumstein, El evangelio (13-21), 296.

69 Servin, “Le deux finales”, 241-247.

70 Mirguet, "Voir la mort”, 469-479.

71 ZUMSTEIn, El evangelio (13-21), 296. La misma opinión recoge Moloney (MoLONEY, “The Gospel of John as Scripture", 454-468).

72 GuiJarro, Los cuatro evangelios, 465-466; Myers, Characterizing Jesus, 37-38. 


\section{Conclusión}

En este trabajo se ha querido mostrar cómo las notas cristológicas del narrador juegan un papel muy significativo en toda la trama del cuarto evangelio, tanto a nivel global, en su estructura, como a lo largo de las distintas secciones de la narración.

El carácter paratextual de estos comentarios -carácter parentético-y al aparecer en la voz autorizada del narrador, que cuenta e interpreta la historia al mismo tiempo, hacen que su contenido quede focalizado en la trama narrativa y llame la atención del lector. De esta manera, estas notas se convierten en la guía de la interpretación adecuada del texto. Por tanto, no deben ser consideradas como glosas secundarias, sino, al contrario, como piezas clave para la interpretación del sentido del texto, en este caso del evangelio joánico.

Las notas cristológicas de Jn 1,17-18; 12,41 y 20,30-31 confirman la clásica estructura del cuarto evangelio, a saber: Prólogo, Libro de los Signos, Libro de la Gloria, Epílogo. Pero estas mismas notas nos permiten ver el evangelio entero como un relato que ha adoptado el género literario de vida antigua para transmitir al lector la verdadera identidad de Jesús, Mesías, Hijo de Dios, de manera que, por medio y gracias al relato, convertido en un "nuevo signo" que transmite la gloria de Jesús, pueda reconfigurar su propia identidad por medio de la fe (20,30-31). Estas tres notas mantienen en la estructura del relato una de las líneas narrativas propias del evangelio de Juan: el "ver" que se convierte en relato y el relato que sustituye, en el tiempo en el que Jesús no es accesible a la visión directa, al "ver".

Las notas cristológicas del narrador acompañan al lector a lo largo de todo el evangelio, salvo en los discursos de despedida (Jn 14-17), para mostrarle el camino de acceso a la fe en Jesús $(1,19-4,54)$, el significado y las consecuencias de su muerte para el creyente $(5,1-12,41)$ y el cumplimiento de toda la revelación de Jesús en la pasión (Jn 13,1-20,31). Ahora esa revelación está contenida en el relato, que se convierte en un libro de fe para el lector.

\section{Bibliografía}

Álamo, F., "La caracterización del personaje novelesco: perspectivas narrativas", Revista Signa 15 (2006) 189-213.

Alvarado, M., Paratexto, Buenos Aires 2006.

Arbona, G., Las llagas y los colores del mundo. Conversaciones literarias con José Jiménez Lozano, Madrid 2011. 
Brown, R., La comunidad del discípulo amado. Estudio de la eclesiología juánica (Biblioteca de Estudios Bíblicos 43), Salamanca ${ }^{3} 1991$.

-, El evangelio según Juan I-XII, Madrid 1999.

CAÑELLES, I., La construcción del personaje literario. Un camino de ida y vuelta, Madrid 1999.

CulPePeer, R. A., Anatomy of the Fourth Gospel. A Study in Literary Design, Philadelfia 1983.

-, "La narratologie et l'évangile de Jean", en J. D. KAestli - J. M. Poffet - J. Zumstein. (eds.), La communauté johannique et son histoire, Geneve 1990, 97-104.

-, "The Narrator in the Fourth Gospel: Intertextual Relantionships", en K. H. Richards (ed.), SBL 1982 Seminar Papers, 81-96.

-, "The Pivot of John's Prologue", New Testament Studies 27 (1980-81) $1-31$.

DodD, C. H., Interpretación del cuarto evangelio, Madrid 1978.

EsCRIBANo Hernández, A., Las voces del texto como recurso persuasivo (Cuadernos de Lengua Española 106), Madrid 2009.

Fuentes RodríGuez, C., "Estructuras parentéticas", LEA 20/2 (1998) 137-174.

-, "Lo oral en lo escrito: los enunciados parentéticos", Moenia 5 (1999) 225-246.

-, "Parentéticos, hedging y sintaxis del enunciado", Clac 55(2013) 61-94.

Guijarro, S., Los cuatro evangelios (Biblioteca de Estudios Bíblicos 124), Salamanca 2010.

-, “¿Por qué comienza así el evangelio de Marcos?”, en R. Trevijano - J. J. Fernández - S. Guijarro (eds.), Plenitudo temporis: Miscelánea homenaje al Prof. Dr. Ramón Trevijano, Salamanca 2002, 133-151.

HEDRICK, C. W., "Authorial Presence and Narrator: Hermeneia and Paradosis", en J. E. Goehring - C. W. Hedrick - J. T. Sanders - H. D. BeTz (eds.), Gospel Origins \& Christian Beginnings. FS J. M. Robinson (Forum Fascicles 1), Sonoma 1990, 74-93.

LÉOn-Dufour, X., Lectura del evangelio de Juan I (Biblioteca de Estudios Bíblicos 8), Salamanca 1993.

MAC LEOD, D. J., "The Benefits of the Incarnation of the Word: John 1:1518", Bibliotheca Sacra 161 (2004) 179-193.

Malbon, E. S., "Ending at the Beginning: A Response", Semeia 52 (1990) 175-184.

Marguerat, D. - Bourquin, Y., Cómo leer los relatos bíblicos. Iniciación al análisis narrativo (Presencia Teológica 106), Santander 2000.

Matera, F. J., New Testament Christology, Louisville 1999. 
Metzger, B. M., A Textual Commentary on the Greek New Testament, Stuttgart - New York ${ }^{2} 1994$.

Mirguet, F., "Voir la mort de Jésus quand le "voir' se fait récit", en G. VAN BeLle (ed.), The Death of Jesus in the Fourth Gospel (Bibliotheca Ephemeridum Theologicarum Lovaniensium 200), Leuven 2007, 469-479.

Myers, A. D., Characterizing Jesus. A Rethorical Analysis on the Fourth Gospel's Use of Scriptures in Its Presentation of Jesus, London 2012.

Moloney, “The Gospel of John as Scripture", The Catholic Biblical Quarterly 67 (2005) 454-468.

O'Rourke, J. "Asides in the Gospel of John", Novum Testamentum 21 (1979) 210-219.

Painter, J., "The Prologue as an Hermeneutical Key to Reading the Fourth Gospel”, en J. Verheyden - G. VAn Dyen - M. Labahn - R. BieRINGER (eds.), Studies in the Gospel of John and its Christology. Festschrift Gilbert Van Belle (Bibliotheca Ephemeridum Theologicarum Lovaniensium 255), Leuven 2014, 37-60.

Ricoeur, P., Historia y narratividad, Barcelona 1999.

Scacewater, T. A., "The Predictive Nature of Typology in John", Westminster Theological Journal 75 (2013) 129-143.

Schnackenburg, R., El evangelio según san Juan, 2 vols., Barcelona 1980.

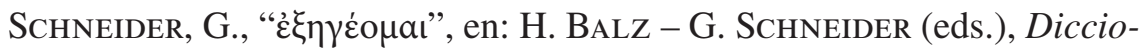
nario exegético del Nuevo Testamento I (Biblioteca de Estudios Bíblicos 90), Salamanca 1996, 1436-1437.

SEvrin, J. M., "Le deux finales du quatrième évangile", en C. Focant - A. WÉNIN (eds.), Analyse narrative et Bible (Bibliotheca Ephemeridum Theologicarum Lovaniensium 191), Leuven 2005, 241-247.

SheEley, S. M., Narrative Asides in Luke-Acts (Journal for the Study of the New Testaments Supplement Series 72), Sheffield 1992.

Staley, J., "The Structure of John's Prologue: Its Implications for the Gospel's Narrative Structure", The Catholic Biblical Quarterly 48 (1986) 241-263.

Tenney, M. C., "The Footnotes of John's Gospel”, Bibliotheca Sacra 117 (1960) 350-364.

Thatcher, T., "A New Look at Asides in The Fourth Gospel", Bibliotheca Sacra 151 (1994) 428-439.

Valles, J., Teoría de la narrativa: una perspectiva sistemática, Madrid 2008.

Van Belle, G., "The Meaning of sēmeia in Jn 20,30-31", Ephemerides Theologicae Lovanienses 74 (1998) 300-325. 
-, Les parenthèses dans l'évangile de Jean. Aperçu historique et classification. Texte grec de Jean, Leuven 1985.

-, "Les parentheses johanniques", en F. Van Segbroeck - C. M. Tukett - G. VAN Belle - J. Verheyden (eds.), The Fourth Gospels 1992. III, Leuven 1992, 1901-1933.

VIDAL, S., Los escritos originales de la comunidad del discípulo "amigo" de Jesús (Biblioteca de Estudios Bíblicos 93), Salamanca 1997.

Zumstein, J., El evangelio según Juan (1-12); El evangelio según Juan (13-21) (Biblioteca de Estudios Bíblicos 152-153), Salamanca 2016.

-, "La naissance de la notion d'Écriture dans la littérature johannique", en J. M. Auwers (ed.), The Biblical Canons (Bibliotheca Ephemeridum Theologicarum Lovaniensium 163), Leuven 2003, 371-394.

-, "Narrativité et herméneutique du Nouveau Testament. La naissance d'un nouveau paradigme", Revue Théologique de Lovain 40 (2009) 324-340.

-, "Le processus de relecture dans la littérature johannique", Études Théologiques et Religieuses 73 (1998) 161-176.

-, "Processus de relecture et reception de l'Écriture dans le quatrième évangile", Estudios Bíblicos 70 (2012) 35-74.

-, "Le prologue, seuil du quatrième évangile", Recherches de Sciencie Religieuse 83 (1995) 217-239.

-, "La rédaction finale de l'évangile selon Jean (À l'exemple du chapitre 21)", en J. D. Kaestli - J. M. Poffet - J. Zumstein (eds.), La communauté johannique et son histoire, Geneve 1990, 207-230.

(recibido: 03/11/17 - aceptado: 06/12/17) 